\title{
USO DO RESÍDUO INDUSTRIAL GRITS EM PAVIMENTOS DE ESTRADAS FLORESTAIS: INFLUÊNCIA DO PERÍODO DE CURA NA RESISTÊNCIA MECÂNICA E EXPANSÃO DE MISTURAS SOLO-GRITS COMPACTADAS ${ }^{1}$
}

\author{
Reginaldo Sérgio Pereira ${ }^{2}$, Carlos Cardoso $\mathrm{Machado}^{3}$, Dario Cardoso de $\mathrm{Lima}^{4}$, Carlos Alexandre Braz de \\ Carvalho $^{4}$ e Danuse Gouvea Machado Pires ${ }^{5}$
}

\begin{abstract}
RESUMO - Analisou-se a influência do teor de estabilizante, da energia de compactação e do período de cura na resistência mecânica e expansão de dois solos da Zona da Mata Norte de Minas Gerais. As amostras de solos residuais de gnaisse coletadas na cidade de Viçosa, MG, Brasil, respectivamente, de texturas argilo-arenosiltosa e areno-argilo-siltosa, foram denominadas solos 1 e 2. Empregou-se como estabilizante químico o resíduo "grits" fornecido pela empresa de Celulose Nipo Brasileira (CENIBRA); os teores, em massa, de 4, 8, 12, 16, 20, 24 e $28 \%$ desse resíduo foram utilizados nas misturas solo-"grits". Corpos-de-prova das misturas solo"grits" foram compactados nos teores ótimos de umidade relativos às energias de compactação dos ensaios Proctor intermediário e modificado e curados por 0, 7,28 e 90 dias. Avaliou-se a resistência mecânica dos solos e misturas através dos seguintes parâmetros: (a) índice de suporte Califórnia (ISC ou CBR), resistência à compressão não confinada (RCNC) e resistência à tração em compressão diametral (Rt). Os resultados permitiram concluir que todos os parâmetros considerados na análise influenciaram, significativamente, a resistência mecânica das misturas solo-"grits", sendo o comportamento das misturas solo 1-“grits" influenciado, também, pelo teor de sódio presente na constituição química do "grits".
\end{abstract}

Palavras-chave: Estradas florestais, estabilização de solos, resíduo "grits".

\section{USE OF INDUSTRIAL GRITS IN FOREST ROAD PAVEMENTS: INFLUENCE OF CURING TIMES ON THE MECHANICAL STRENGTH AND SWELLING OF COMPACTED SOIL-GRITS MIXTURES}

\begin{abstract}
This paper addresses the influence of stabilizer content, compaction effort and curing time on the mechanical strength and swelling of two soils from the "Zona da Mata Norte" region, State of Minas Gerais, Brazil. Two residual gneiss soils from the municipality of Viçosa, Brazil, silt-sand-clay and silt-claysandy soils named soils 1 and 2, respectively, were used in this study. Industrial grits provided by Celulose Nipo Brasileira - CENIBRA was used as stabilizer, with contents ranging from 4 to $28 \%$ regarding soil dry mass. Specimens of soil-grits mixtures were compacted at the Intermediate Proctor compaction effort and curing times of 0, 7, 28 and 90 days. Mechanical strength was evaluated as follows: California bearing ratio $(C B R)$, unconfined compression strength (UCS) and indirect tensile strength (ITS). Data from the laboratorytesting program supported that all parameters affected mixture mechanical strength significantly, and the mechanical behavior of soil 1-grits mixtures were also influenced by sodium content of grits.
\end{abstract}

Keywords: Forest roads, soil stabilization, industrial grits.

\footnotetext{
${ }^{1}$ Recebido em 13.07.2005 e aceito para publicação em 05.04.2006.

${ }^{2}$ Departamento de Engenharia Florestal da UnB, Brasília, Brasil. E-mail: <reginaldosp1@yahoo.com.br>.

${ }^{3}$ Departamento de Engenharia Florestal da UFV, 36570-000 Viçosa-MG, Brasil. E-mail: <machado@ufv.br>.

${ }^{4}$ Departamento de Engenharia Civil da UFV, Viçosa-MG, Brasil. E-mail:<declima@ufv.br>.

${ }^{5}$ Bolsista de Iniciação Científica do Departamento de Engenharia Florestal da UFV, Viçosa-MG, Brasil.
} 


\section{INTRODUÇÃO}

Na construção de camadas de pavimentos rodoviários, quando se faz uso de solos incorporados com aditivos químicos e compactados, um aspecto primordial a ser considerado é a evolução da resistência mecânica com o aumento do período de cura. Tomando por base os solos reativos ao emprego dos estabilizantes químicos tradicionais cal e cimento após a definição do teor ótimo de agente estabilizante em função do tipo de solo, quando essas misturas são compactadas e curadas, notou-se que as misturas solo-cimento atingiram incrementos significativos de resistência mecânica, entre os períodos de 7 e 28 dias de cura (BUENO, 1996); de forma análoga, as misturas solocal compactadas tiveram, segundo Mendonça (1998), maiores incrementos de resistência mecânica entre 28 e 90 dias de cura. As duas experiências foram com solos característicos da microrregião de Viçosa, MG.

Em se tratando das misturas solo-cal, uma das razões para ganhos de resistência dessas misturas compactadas e curadas é a ocorrência das reações pozolânicas entre o material inorgânico e o hidróxido de cálcio formando compostos insolúveis mesmo sob condições de imersão, indispensáveis à formação de produtos cimentantes das partículas do solo (NÓBREGA, 1988; LIMA et al., 1993; ALCÂNTARA, 1995). Thompson (1967), referindo-se à resistência ao cisalhamento da mistura solo-cal, descreveu que esta pode ser potencializada pelo gradual desenvolvimento das reações pozolânicas com o tempo de cura por períodos superiores até 10 anos. Vieira et al. (1986) detectaram em amostras da base de um pavimento de solo-cal construído na RJ-116 em 1973, perfazendo, portanto, 13 anos na época da coleta, a presença de óxido de magnésio ( $\mathrm{MgO})$, evidenciando-se que a atividade pozolânica ou o processo de geopolimerização ainda não havia sido encerrado, melhorando, assim, ao longo do tempo, características como a resistência mecânica. McDowell (1966) constatou o fato anterior quando amostras extraídas da base de um pavimento de solo-cal nos Estados Unidos, construído há 10 anos, apresentaram valores de resistência três vezes maiores do que amostras ensaiadas com os mesmos agentes em laboratório.

Assim, o presente estudo teve como objetivo avaliar em laboratório, via ensaios de capacidade de suporte $\mathrm{CBR}$, a resistência à compressão não confinada (RCNC) e a resistência à tração (Rt), o comportamento mecânico de misturas solo-grits compactadas e submetidas a diferentes períodos de cura para emprego em estradas florestais.

\section{MATERIAL E MÉTODOS}

\subsection{Identificação do material}

As amostras de solo foram provenientes de perfis comuns aos solos da microrregião de Viçosa, MG, tipicamente residuais e originários de gnaisse; essas amostras foram frutos de experiências anteriores em estudos de estabilização química de solos com o emprego de resíduos industriais (MACHADO et al., 2001; SANT'ANNA et al., 2003). Uma das ocorrências denominadas por solo 1 trata-se de um Latossolo Vermelho-Amarelo representativo do manto superficial maduro, horizonte $\mathrm{B}$, bastante intemperizado, tendo em sua constituição textural $70 \%$ de argila. Essa amostra é classificada pelo sistema rodoviário americano Transportation Research Board (TRB) como A-7-5 (20). A outra amostra de solo do trabalho denominada por solo 2 refere-se ao manto saprolítico, horizonte C profundo, de textura predominantemente arenosa (74\%); sendo classificada pelo sistema TRB como A-2-4 (0). Empregou-se como estabilizante químico dos solos o resíduo grits, cedido pela empresa de Celulose Nipo Brasileira (CENIBRA); esse resíduo sólido, gerado durante o processo de recuperação da soda cáustica no processo "kraft" de extração de celulose, possui granulometria diversificada e presença em sua composição química de óxido de cálcio, componente essencial para a reatividade das misturas solo-cal e solo-cimento.

\subsection{Misturas realizadas}

Os seguintes teores de grits foram utilizados em massa de solo seco: (a) 4, 8, 12, 16, 20, 24 e 28\% no caso dos ensaios de CBR (índice de suporte california) e (b) 16,20 e $28 \%$ no caso dos ensaios de RCNC (resistência à compressão não-confinada) e Rt (resistência à tração em compressão diametral). Adicionou-se água nas misturas solo-grits em quantidades para atingir teores de umidade ótima prédeterminados em ensaios de compactação referentes às energias dos ensaios do Proctor intermediário e modificado.

\subsection{Ensaios de resistência e períodos de cura das misturas solo-grits}

A avaliação da resistência de cada mistura sologrits foi feita através dos ensaios de CBR (DNIT, 1994a), RCNC e Rt com a compactação realizada nas energias 
de compactação referentes aos ensaios Proctor intermediário e modificado. A moldagem dos corposde-prova empregados na determinação da RCNC e da Rt seguiu a normalização técnica do DNIT (1994d), cujas características de compactação são: (a) o molde empregado é o cilindro-padrão de Proctor $(\phi=10 \mathrm{~cm}$ e $\mathrm{h}=12 \mathrm{~cm}$ ) e (b) a compactação é realizada em camadas por processo dinâmico com soquete de $4,5 \mathrm{~kg}$. Foram confeccionados três corpos-de-prova para cada tratamento e o controle da homogeneidade obtido através do grau de compactação (GC), aceitando-se um desvio de $100 \pm 0,5 \%$

Após a confecção e antes da ruptura em prensa específica, os corpos-de-prova foram submetidos aos seguintes períodos de cura: (a) ensaio CBR - 0, 7 e 28 dias, em câmara úmida, seguido posteriormente por quatro dias de imersão em água para medição do índice de expansão; e (b) ensaio RCNC e Rt - 0, 7, 28 e 90 dias, embalados em sacos plásticos e colocados em câmara úmida, sendo a ruptura dos corpos-de-prova realizada através do ensaio de RCNC, segundo a recomendação da norma DNIT (1994c), e para o ensaio de Rt, a recomendação da norma DNIT (1994b).

\section{RESULTADOS E DISCUSSÃO}

\subsection{Influência do período de cura no CBR e expansão ${ }_{\mathrm{CBR}}$ das misturas solo-grits}

Os resultados dos ensaios de CBR e expansão ${ }_{\mathrm{CBR}}$ das misturas solo-grits curadas e não curadas, após a compactação, encontram-se ilustrados nas Figuras 1 e 2. As misturas solo 1-grits (Figura 1) alcançaram melhores resultados de CBR quando não curadas com valores superiores ao encontrado no solo 1 sem adição do resíduo. Tomando-se por base os valores de CBR de 14 e $16 \%$ no solo 1 , respectivamente, quando compactado na energia intermediária e modificada, as melhores respostas obtidas para as misturas não curadas foram: (a) na energia intermediária - mistura solo $1+28 \%$ grits $(\mathrm{CBR} \cong 32 \%)$ e (b) na energia modificada - misturas solo $1+24 \%$ grits e solo $1+28 \%$ grits $(\mathrm{CBR} \cong 20 \%)$. Com relação aos períodos de cura de 7 e 28 dias, observaram-se valores de CBR inferiores ao do solo $1 \mathrm{em}$ sua forma natural, mesmo durante o emprego de maior esforço de compactação (valores de $\mathrm{CBR}<15 \%$ na energia modificada). Uma das razões para a ocorrência desse fato está na porcentagem de sódio $(0,70 \%)$ presente na constituição química do grits que provavelmente, com o tempo de cura, levou as partículas finas do solo 1 à dispersão, resultando em baixos valores de CBR das misturas.

Na Figura 1 é possível observar, também, o comportamento das misturas solo 1-grits com relação ao índice de expansão. Com 7 e 28 dias, notaram-se menores valores nas misturas solo 1 -grits compactadas, o que evidencia a ação do sódio no solo 1, ou seja, devido à dispersão das partículas de argila, causada pelo íon sódio, quando os corpos-de-prova foram imersos em água essa dispersão não encontrou barreira para penetrá-los ocasionando menores valores em comparação com a expansão das misturas não-curadas. Atentase, também, para os valores de expansão encontrados nas misturas solo 1-grits compactadas na energia modificada e não-curadas, em que se atingiram valores de expansão superiores a $0,50 \%$, condição essa que o solo 1 não possuía em sua forma natural.

Na Figura 2, encontram-se os resultados de CBR e expansão das misturas solo 2-grits. O solo 2 teve seus valores de CBR na energia intermediária e modificada aumentados, quando da adição de grits. Comportamentos distintos foram observados em função da energia de compactação empregada: (a) na energia intermediária, as melhores respostas obtidas foram para as misturas solo-grits não-curadas, sendo notados nos traços de 12 até $28 \%$ de grits aumentos nos valores de CBR; em termos de ganhos percentuais, em relação ao solo 2, esses aumentos de CBR variaram de 50 até $200 \%$; e (b) na energia modificada, comparando os resultados das misturas solo 2-grits não-curadas e curadas aos sete dias, notaram-se ganhos significativos nos valores de CBR decorrentes da realização da cura em todos os traços de resíduo empregados, sendo as melhores respostas de CBR alcançadas nas misturas com 24 e $28 \%$ de grits, curadas aos sete dias, quando, respectivamente, o CBR atingiu valores aproximados de 120 e $160 \%$. No intervalo de cura entre 7 e 28 dias não foram observados nas misturas solo 2-grits aumentos expressivos nas taxas de ganhos de CBR, ficando os valores muito próximos.

Ainda pela Figura 2, nota-se que os valores de expansão das misturas solo 2-grits compactadas na energia intermediária sofreram poucas oscilações em decorrência do período de cura, ficando inferiores a $0,50 \%$. Na energia modificada, essas mesmas misturas, quando não-curadas, atingiram valores de expansão

R. Árvore, Viçosa-MG, v.30, n.5, p.795-802, 2006 
superiores aos encontrados quando de cura de 7 e 28 dias; nesses dois últimos períodos, os valores de expansão foram inferiores a $0,50 \%$ na maioria das misturas. Ressalta-se que solo 2 compactado na energia modificada e imerso dentro do cilindro califórnia, apesar de possuir predominância da fração areia, expandiu-se, o que foi evidenciado por seu elevado valor de expansão (3,50\%). Em mistura com o grits, possíveis reações de troca catiônica dependentes do período de cura ocorrerem, levando à formação de compostos que retêm a entrada da água.

\subsection{Influência do período de cura na RCNC e Rt das misturas solo-grits}

Os resultados dos ensaios de resistência à compressão não confinada (RCNC) e de resistência à tração $(\mathrm{Rt})$ encontram-se ilustrados nas Figuras 3 e 4. Considerando-se os valores de RCNC das misturas solo 1-grits (Figura 3), as melhores respostas obtidas foram para as misturas em que não foram realizadas cura úmida para compactação, tanto na energia intermediária quanto na modificada. Verificaram-se decréscimos nos valores de RCNC a partir do período de sete dias de cura em todas as misturas e energias empregadas. Os corpos-de-prova compactados quando curados, principalmente, aos 90 dias expandiram e apresentaram inúmeras fissuras em razão, provavelmente, da ação dispersiva do sódio. Outro fato a considerar é que após a realização das misturas solo 1-grits, devido à ocorrência de trocas catiônicas entre as partículas do solo 1 e o grits, elas ficaram excessivamente pegajosas, o que dificultou o efeito da compactação pela dificuldade de manipulação por parte dos operadores, do soquete compactador.

A adição de grits ao solo 1 proporcionou quedas drásticas no seu valor de RCNC; para a compactação na energia intermediária, notaram-se taxas de reduções que variaram, dependendo do teor de resíduo e do período de cura empregados, de 0 até $58 \%$; de forma análoga, na energia modificada essas taxas tiveram variações de 43 até $73 \%$ (taxa observada na mistura com $28 \%$ de grits curada a 28 dias).

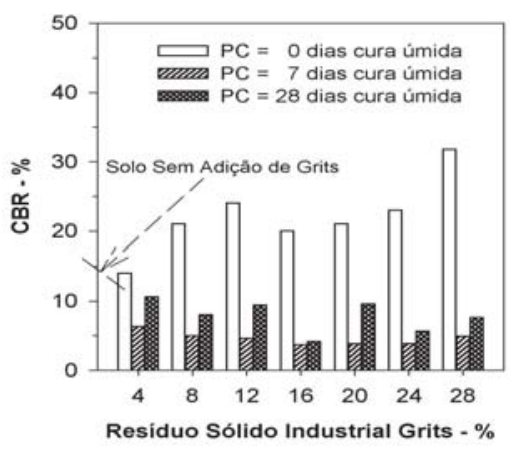

a) Compactação na Energia Intermediária

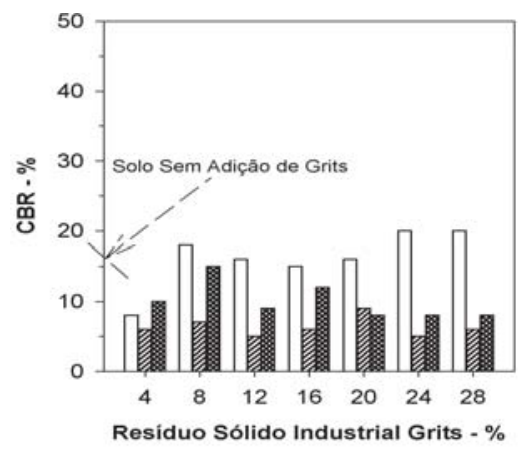

b) Compactaçăo na Energia Modificada

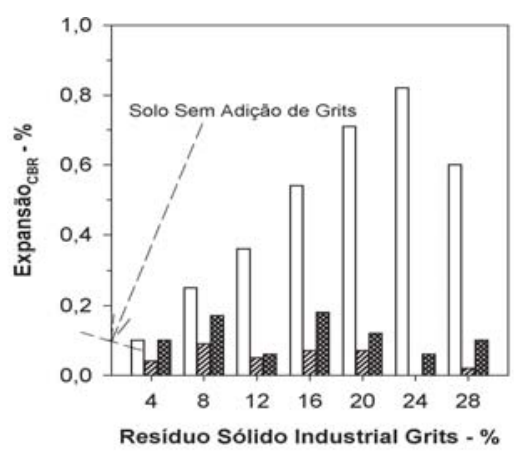

d) Compactaçẫo na Energia Modificada

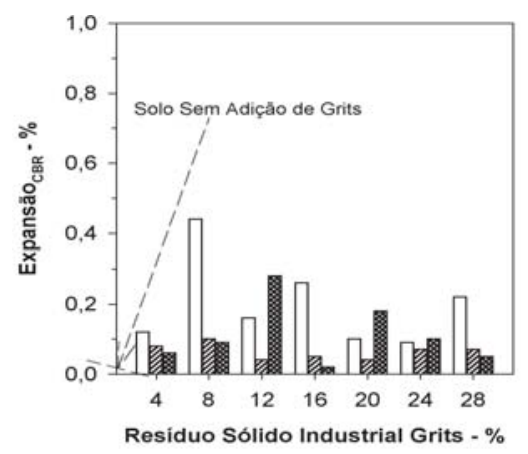

c) Compactaçăo na Energia Intermediária

Figura 1 - Efeito do período de cura no CBR e expansão ${ }_{\mathrm{CBR}}$ das misturas solo 1-"grits".

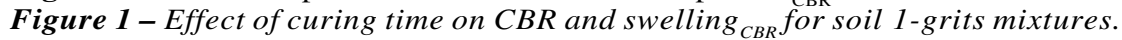



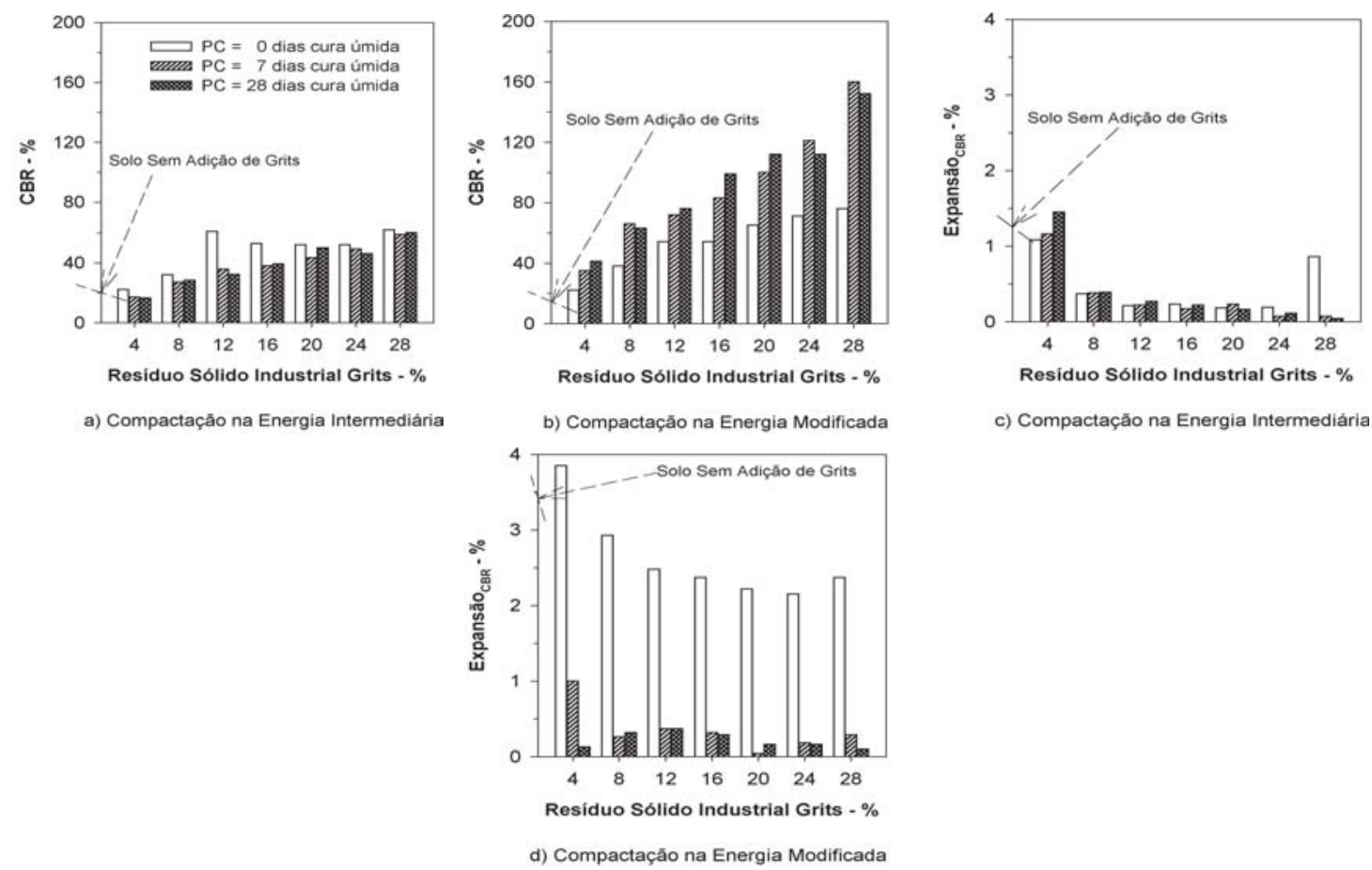

c) Compactaçăo na Energia Intermediária

Figura 2 - Efeito do período de cura no CBR e expansão ${ }_{\mathrm{CBR}}$ das misturas solo 2-"grits".

Figure 2-Effect of curing time on CBR and swelling ${ }_{C B R}$ for soil 2-grits mixtures.

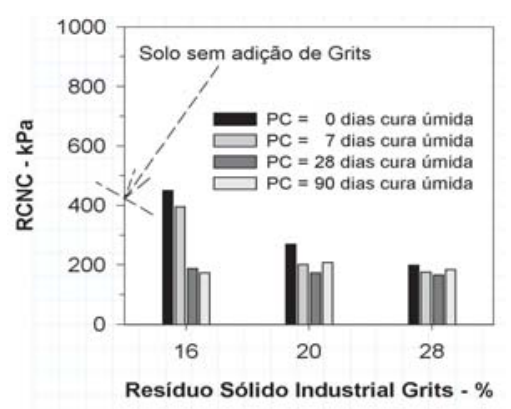

a) Compactação na Energia Intermediária

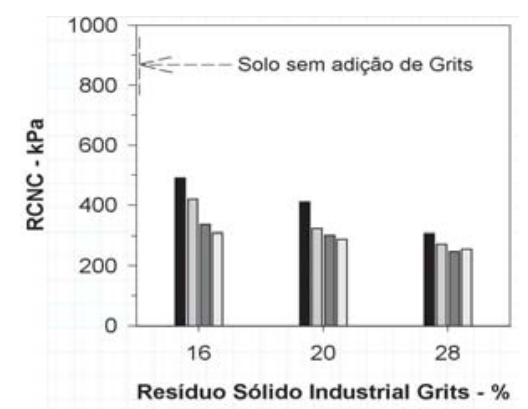

b) Compactação na Energia Modificada

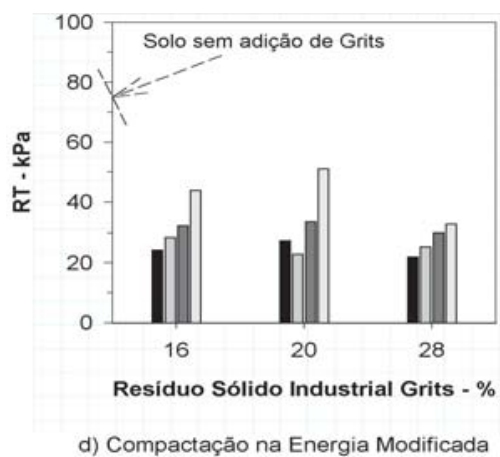

d) Compactaçăo na Energia Modificada

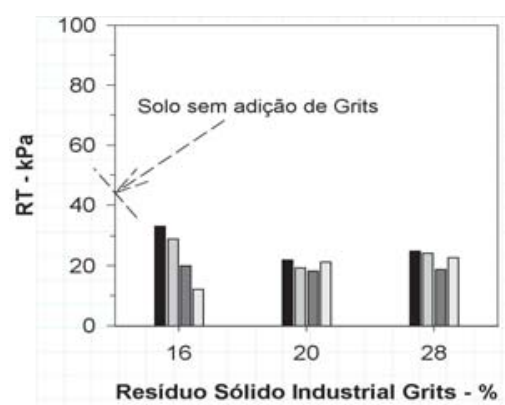

c) Compactação na Energia Intermediária

Figura 3 - Efeito do período de cura na RCNC média e Rt média das misturas solo1-“grits".

Figure 3 - Effect of curing time on mean UCS and mean ITS for soill-grits mixtures. 
Com relação à resistência à tração, as misturas solo 1-grits tiveram o seguinte comportamento: (a) $\mathrm{Na}$ energia intermediária - todas as misturas solo 1-grits tiveram valores de Rt inferiores ao do solo 1 sem adição de resíduo. Nas misturas com $16 \%$ de grits houve redução exponencial a partir de sete dias de cura, sendo com 90 dias obtido um valor $60 \%$ menor do que o encontrado na mesma mistura não-curada; os valores de Rt nas misturas com 20 e $28 \%$ de grits praticamente não sofreram alterações em função do período de cura; (b) Na energia modificada - ocorreram taxas de incremento na maioria dos tratamentos; na mistura com $20 \%$ de grits, notouse maior aumento de Rt entre os períodos de cura entre 28 e 90 dias ( $\cong 35 \%)$. Entretanto, nessa energia também em todas as misturas os valores de Rt foram inferiores às do solo 1 em sua forma natural. Nas misturas solo 2grits (Figura 4) ocorreram, também, reduções nos valores de RCNC a partir do período de cura de sete dias, quando da compactação na energia intermediária; os maiores valores desse parâmetro foram obtidos nas misturas não-curadas. A adição de grits ao solo 2 na maioria dos teores e períodos de cura proporcionou, nessa energia de compactação, ganhos nos valores de RCNC que atingiram mínimos de $2 \%$ a máximos de $88 \%$ (caso da mistura solo $2+28 \%$ grits sem cura). Na energia modificada, as misturas solo 2-grits tiveram o seguinte comportamento: (a) Nos teores de 16 e $20 \%$ de grits ocorreram incrementos nos valores de RCNC entre as curas de 0 e 7 dias e entre 7 e 28 dias, observandose queda com cura de 90 dias; com $16 \%$ de grits, notaramse $38 \%$ (entre 0 e 7 dias) e $5 \%$ (entre 7 e 28 dias) na taxa de ganho de RCNC; de forma análoga, $24 \%$ (entre 0 e 7 dias) e $10 \%$ (entre 7 e 28 dias), quando o teor de grits foi de $20 \%$. No teor de $28 \%$ de grits, notouse aumento de $9 \%$ de RCNC entre 0 e 7 dias de cura e no intervalo de cura de 28 e 90 dias queda. (b) Com exceção do teor de $28 \%$ de grits e cura de 90 dias, em todas os demais tratamentos, notaram-se ganhos de RCNC em relação ao valor obtido no solo $2 \mathrm{em} \mathrm{seu}$ estado natural, com variações de 0 (caso da mistura com $28 \%$ grits curada a 28 dias) até $138 \%$ (caso da mistura com $20 \%$ grits curada a 28 dias).

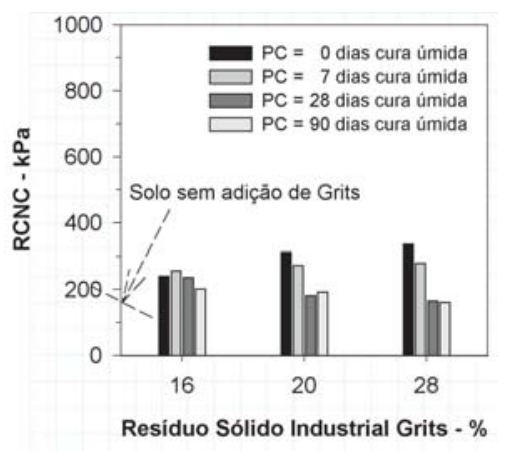

a) Compactação na Energia Intermediária

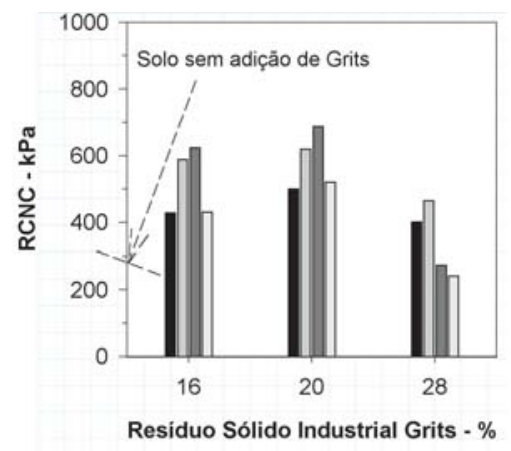

b) Compactação na Energia Modificada

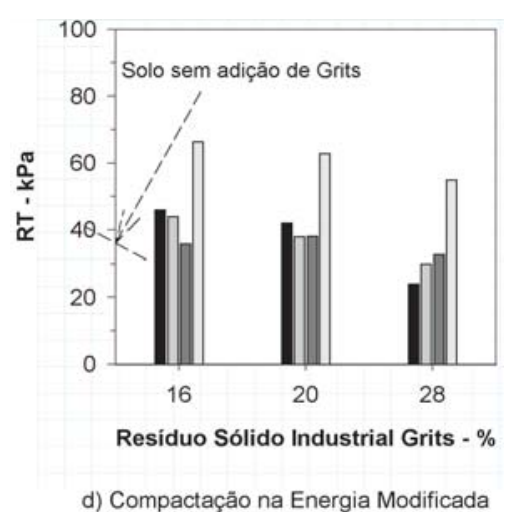

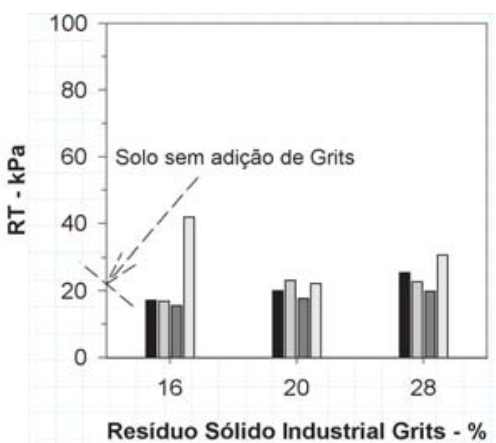

c) Compactação na Energia Intermediária

Figura 4 - Efeito do período de cura na RCNC média e Rt média das misturas solo2-"grits".

Figure 4-Effect of curing time on mean UCS and mean ITS for soil2-grits mixtures. 
Com os valores de Rt obtidos nas misturas solo 2grits, evidenciaram-se na energia intermediária maiores incrementos de Rt entre os períodos de cura de 28 e 90 dias; na mistura com $16 \%$ de grits, atingiu-se a maior taxa de ganho de Rt ( $\cong 170 \%$ ). Nessa mesma mistura e período de cura de 90 dias, o ganho de Rt em relação ao solo 2 foi de $86 \%$, valor máximo encontrado. Nra compactação em energia modificada, os resultados prescreveram o seguinte: (a) os maiores incrementos de Rt foram, também, entre as curas de 28 e 90 dias, com ganhos de aproximadamente 88,59 e $51 \%$, respectivamente, nos teores de 16, 20 e $28 \%$ de grits; e (b) a maior taxa de ganho de Rt em relação ao solo 2 foi no teor de $16 \%$ de grits e cura de 90 dias (aumento de $79 \%$ ).

\section{CONCLUSÕES}

As misturas solo-grits sofreram influência tanto do teor de resíduo empregado e da energia de compactação quanto do período de cura a que foram submetidas, o que foi evidenciado pelos ensaios de resistência e expansão. As misturas solo 1-grits tiveram seus valores de resistência e expansão influenciados pelo teor de sódio presente no resíduo, o que não proporcionou taxas de incremento na resistência dessas misturas em função do período de cura, sendo as melhores respostas obtidas nas misturas não-curadas, considerando-se ambas as energias de compactação; exceção seja feita às misturas compactadas na energia modificada, em que os valores de Rt evidenciaram ganhos no período de 90 dias de cura. Nas misturas solo 2grits compactadas na energia intermediária, a cura não surtiu efeito em termos de ganhos de resistência com melhores respostas obtidas nas misturas não-curadas, exceção feita aos dados de Rt, em que as melhores respostas foram para 90 dias de cura. Quando compactadas na energia modificada, essas mesmas misturas tiveram ganhos significativos de resistência mecânica entre o intervalo de cura de 0 e 7 dias; considerando-se os ensaios de CBR e de RCNC e entre 28 e 90 dias, considerando-se o ensaio de Rt. Ressaltase também que, nessa energia, notaram-se elevados valores de expansão quando as misturas não foram submetidas à cura.

\section{AGRADECIMENTOS}

Ao CNPq e à FAPEMIG, pelo apoio financeiro ao projeto, bem como à CAPES, pelo fornecimento da bolsa de doutorado. Igual agradecimento à Empresa CENIBRA, pelo fornecimento do resíduo; e à Universidade Federal de Viçosa, pelas instalações.

\section{REFERÊNCIAS BIBLIOGRÁFICAS}

\author{
ALCÂNTARA, M.A.M. Estabilização \\ química dos solos para fins \\ rodoviários: técnicas disponíveis e \\ estudo de caso dirigido à estabilização \\ solo-cal de três solos de Ilha Solteira- \\ SP. 1995. 91 f. Dissertação (Mestrado em \\ Geotecnia) - Universidade Federal de Viçosa, \\ Viçosa, MG, 1995.
}

BUENO, B.S. Aspectos da estabilização de solos com uso de aditivos químicos e de inclusões plásticas aleatórias. 1996. Concurso Público (Livre Docência) Universidade de São Paulo, São Carlos, 1996.

\section{DEPARTAMENTO NACIONAL DE INFRA-} ESTRUTURA DE TRANSPORTES - DNIT. ME 129: Solos: compactação utilizando amostras não trabalhadas. Rio de Janeiro: 1994a. 7 p.

DEPARTAMENTO NACIONAL DE INFRAESTRUTURA DE TRANSPORTES - DNIT. ME

181: solos estabilizados com cinza volante e cal hidratada: determinação da resistência a tração por compressão diametral. Rio de Janeiro: 1994b. 7 p.

\section{DEPARTAMENTO NACIONAL DE INFRA-} ESTRUTURA DE TRANSPORTES - DNIT. ME

201: solo-cimento: compressão axial de corpos-deprova cilíndricos. Rio de Janeiro: 1994c. 12 p.

\section{DEPARTAMENTO NACIONAL DE INFRA-} ESTRUTURA DE TRANSPORTES - DNIT. ME 202: solo-cimento: moldagem e cura de corposde-prova cilíndricos. Rio de Janeiro: 1994d. 9 p.

LIMA, D.C.; RÖHM, S.A.; BARBOSA, P.S.A. Estabilização dos solos III: mistura solocal para fins rodoviários. Viçosa, MG: Universiade Federal de Viçosa, 1993. 46 p. (Publicação, 334).

MACHADO, C.C. et al. Avaliação da resistência mecânica de misturas solo-alcatrão de madeira (fracionado e não-fracionado) para estradas florestais. Revista Árvore, v. 25, n. 1, p. 9-17, 2001.

R. Árvore, Viçosa-MG, v.30, n.5, p.795-802, 2006 
McDOWELL, C. Evaluation of soil-lime stabilization mixtures. In: HIGHWAY RESEARCH RECORD, 139., Washington, D.C. Record... Washington, D.C: HRB, 1966. p. 15-24.

MENDONÇA, A.A. Caracterização tecnológica de misturas solo-cal. 1998. 109 f. Dissertação (Mestrado em Geotecnia)Universidade Federal de Viçosa, Viçosa, MG, 1998.

NÓBREGA, M.T. A estabilização de solos tropicais com adição de cal para fins rodoviários. 1988.115 f. Dissertação

(Mestrado em Geociências)-Universidade de São Paulo, São Paulo, 1988.
SANT'ANNA, G.L. et al. Módulo de resiliência de um solo arenoso e de suas misturas com alcatrão fracionado e cal. Revista Árvore, v. 27, n. 4, p. 527-534, 2003.

THOMPSON, M.R. Shear strength and elastic properties of lime-soil mixtures. Washington, D.C.: Highway Research Record, 1967. p. 1-14. (Bulletin, 139).

VIEIRA, R.I. et al. Avaliação de um trecho de solo-cal na RJ - 116. In: REUNIÃO ANUAL DE PAVIMENTAÇÃO, 21., 1986, Salvador, Bahia. Anais... Salvador: 1986. Paginação irregular. 